\title{
Erratum to: Duration of wound fluid secretion from chronic venous leg ulcers is critical for interleukin-1 $\alpha$, interleukin-1 $\beta$, interleukin-8 levels and fibroblast activation
}

Rikke Zillmer • Hannah Trøstrup •

Tonny Karlsmark $\cdot$ Peter Ifversen •

Magnus S. Ågren

Published online: 6 November 2011

(C) Springer-Verlag 2011

Erratum to: Arch Dermatol Res (2011) 303:601-606

DOI 10.1007/s00403-011-1164-6

The corresponding author would like to correct the error on page 4 , second line, left column it says incorrectly that "Eleven patients, 9 males and 2 females,...". The correct sentence should read "Eleven patients, 9 females and 2 males".

The online version of the original article can be found under doi:10.1007/s00403-011-1164-6.

R. Zillmer · H. Trøstrup · T. Karlsmark · M. S. Ågren ( $\square)$

Department of Dermatology, Copenhagen Wound Healing

Center, Bispebjerg Hospital, University of Copenhagen,

Bispebjerg Bakke 23, 2400 Copenhagen NV, Denmark

e-mail:saag0005@bbh.regionh.dk

P. Ifversen

Global R\&D, Coloplast A/S, Humlebæk, Denmark

M. S. Ågren

Department of Surgery K, Bispebjerg Hospital,

University of Copenhagen, Copenhagen, Denmark 